\title{
Influência do El Niño Oscilação Sul - ENOS - (2015/2016) no regime hidrológico e geração de energia na usina hidrelétrica de Curuá-Una, Amazônia central
}

O objetivo deste estudo foi analisar a influência do evento El Niño Oscilação Sul (ENOS), ocorrido no período de 2015 a 2016, na variabilidade de eventos extremos de chuva-vazão, nível e geração de energia observada no reservatório da hidrelétrica de Curuá-Una. Os dados de geração de energia elétrica foram utilizados para avaliar o efeito dos eventos extremos de chuva-vazão. Os efeitos do ENOS (2015/2016) foram: a redução em torno de $50 \%$ na precipitação pluvial no período chuvoso e no período menos chuvoso, com ausência de precipitação nos meses de outubro e novembro; o decaimento do nível do reservatório a montante, chegando a $60 \mathrm{~m}$; a redução (em torno de $150 \mathrm{~m}^{3} / \mathrm{s}$ ) na vazão média no período chuvoso, influenciado por El Niño muito forte como o que ocorreu em 2016 e 0 decaimento da geração média de energia de $25 \mathrm{MW} / \mathrm{h}$ para $10 \mathrm{MW} / \mathrm{h}$. Os resultados mostram que o regime hidrológico do reservatório de Curuá-Una foi fortemente afetado pela atuação do ENOS com consequente redução da geração de energia elétrica.

Palavras-chave: Chuva-vazão; Eventos extremos; Santarém/PA.

\section{Influence of El Niño Southern Oscillation - ENSO - (2015/2016) in the hydrological variability and in the power generation in Curua-Una hydroelectric power plant, central Amazon}

\begin{abstract}
The aim of this study was to analyze the influence of the El Niño Southern Oscillation (ENSO) event, which happened from 2015 to 2016 , on the variability of extreme rainfall-flow events, level and power generation observed in the Curuá-Una power plant reservoir. The electric power generation data were used to evaluate the effect of extreme rainfall-flow events. The effects of the ENSO $(2015 / 2016)$ were: the reduction of around $50 \%$ in the rainfall in the rainy season and in the less rainy season, with no precipitation in October and November; the decay of the reservoir level upstream, reaching $60 \mathrm{~m}$; the reduction (around $150 \mathrm{~m}^{3} / \mathrm{s}$ ) in the average flow in the rainy season, influenced by very strong El Niño, as occurred in 2016 and the decay of the average energy generation from $25 \mathrm{MW} / \mathrm{h}$ to $10 \mathrm{MW} / \mathrm{h}$. The results show that the hydrological regime of the Curuá-Una reservoir was strongly affected by the ENOS activity, with a consequent reduction in the electric power generation.
\end{abstract}

Keywords: Rain-flow; Extreme events; Santarém/PA.

Leidiane Leão de Oliveira (iD)

Universidade Federal do Oeste do Pará, Brasil http://lattes.cnpq.br/5016148560650320 http://orcid.org/0000-0002-5995-9107

leidianeoli@gmail.com

Tatiane Maiza Rodrigues Silva

Universidade Federal do Oeste do Pará, Brasil http://lattes.cnpq.br/6888631940823866 maizatrs@hotmail.com

Naurinete de Jesus da Costa Barreto (iD Instituto Nacional de Pesquisas Espaciais, Brasil http://lattes.cnpq.br/9415435965900811 http://orcid.org/0000-0001-5167-6228 netebarreto@gmail.com

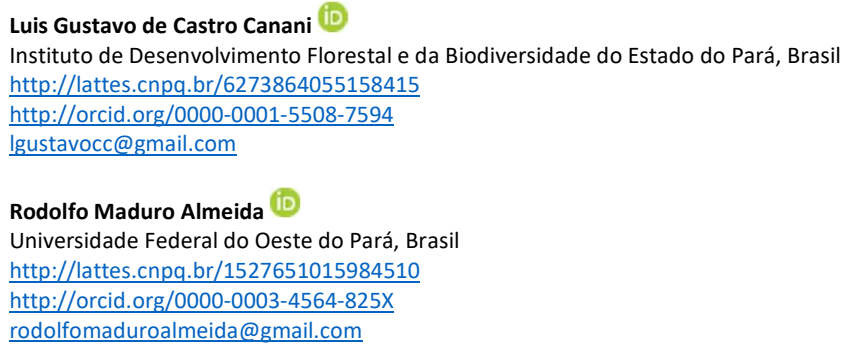


Influência do El Niño Oscilação Sul - ENOS - (2015/2016) no regime hidrológico e geração de energia na usina hidrelétrica de Curuá-Una,

\section{INTRODUÇÃO}

No Brasil, a energia hidráulica é de grande importância para o desenvolvimento econômico e na integração de regiões distantes dos grandes polos urbanos e industriais. De acordo com Marengo (2008), em relação à disponibilidade de recursos hídricos, o país possui posição privilegiada e a responsabilidade por grande parte dessa água é o clima. O ciclo anual de precipitações e de vazões varia entre bacias, a variabilidade interanual do clima está associada aos fenômenos de El Niño, La Niña, ou à variabilidade na temperatura da superfície do mar do Atlântico Tropical e Sul que podem gerar desequilíbrios climáticos. São compreendidas como eventos extremos as cheias e as secas. As cheias estão associadas com eventos de precipitação de grande magnitude, enquanto as secas caracterizam-se pelo período com ausência de precipitações e altas temperaturas (CARVALHO NETO et al., 2014).

O El Niño é uma anomalia cíclica, um episódio pode durar em média de 9 a 12 meses, normalmente atingindo seu pico no final do ano. Este fenômeno pode afetar o clima regional e global, interferindo os padrões de vento a nível mundial e influenciando os regimes de chuva e temperatura em regiões tropicais. Dentre as preocupações diagnosticadas com a ocorrência de um evento anômalo está uma maior probabilidade de um baixo índice pluviométrico sazonal, atingindo diretamente os mananciais hídricos.

A Bacia Amazônica é a mais extensa, de maior densidade de água do mundo e representa o maior potencial energético do país. A energia hidroelétrica é gerada através do aproveitamento do fluxo das águas, o qual é considerado como o principal atributo hidrológico de um rio, pois ele é responsável pela estrutura hidrológica geológica do canal (AGOSTINHO et al., 2008). Sendo, porém, a quantidade de água armazenada em um reservatório energético fator determinante para que uma usina hidrelétrica tenha capacidade para produzir energia, no qual depende da vazão fornecida pelo rio e está inerente ao regime de chuvas em que a bacia hidrográfica esteja submetida. Por isso, a variação climática de uma região traz consequências importantes para o sistema de energia elétrico brasileiro (DALLEDONNE, 2011).

A vazão trata-se do volume de água que escoa por uma determinada seção transversal em um intervalo de tempo considerado (REIS et al., 2011). Cada usina possui suas informações armazenadas em um banco de dados. Atualmente, o Operador Nacional do Sistema (ONS) é o agente responsável que gerencia e disponibiliza um banco de dados contendo o registro de série histórica de vazões de todas as usinas hidrelétricas que compõem o SIN (Sistema interligado Nacional). Dentre as vazões, verifica-se: a) a vazão afluente que chega pelo montante e através de seus afluentes; b) vazão turbinada: passa pela turbina e gera energia; c) vazão vertida: não gera energia; d) vazão defluente: liberada pela barragem.

A Usina Hidroelétrica de Curuá-Una, está situada na cidade de Santarém, no rio Curuá-Una afluente da margem direita do rio Amazonas. O município de Santarém está localizado na região Oeste do Pará, no baixo Amazonas. O projeto de aproveitamento da UHE de Curuá-Una, iniciou na década de 60 , com o objetivo de abastecimento elétrico na cidade de Santarém e a região de Aveiro. A capacidade do potencial prevista para a Usina seria de $40 \mathrm{MW}$ com a instalação de 4 turbinas. No entanto, a demanda energética foi maior devido ao aumento do crescimento populacional na região. Contudo, a mesma foi inaugurada em agosto de 
1977, com potência útil de 30 MW e três turbinas. A UHE de Curuá-Una não possui capacidade máxima para o abastecimento local, tem como finalidade suprir a deficiência nos momentos de pico de consumo, esse processo se dá através do Sistema Interligado Nacional (SIN).

Este trabalho teve como objetivo analisar a influência do evento El Niño Oscilação Sul - ENOS, ocorrido no período de 2015 a 2016, na variabilidade de eventos extremos de chuva-vazão e geração de energia observada no reservatório da hidrelétrica de Curuá-Una.

\section{METODOLOGIA}

\section{Área de Estudo}

A Usina Hidrelétrica de Curuá-Una abrange uma área de $72 \mathrm{~km}^{2}$, construída sobre o rio Curuá-Una e seus afluentes rios Moju, Mojuí dos Campos e Poraquê. Está situada a $80 \mathrm{~km}$ ao sul de Santarém-PA ( $2^{\circ}$ 24'52"S; 54¹7'30"W) (Figura 1). O clima da região Oeste do estado do Pará, é quente e úmido, típico das Florestas Tropicais. Devido sua proximidade à linha do Equador, não há variação significativa de temperatura, constituindo uma média anual que varia entre 25 a $29^{\circ} \mathrm{C}$ (ARAÚJO, 2007).
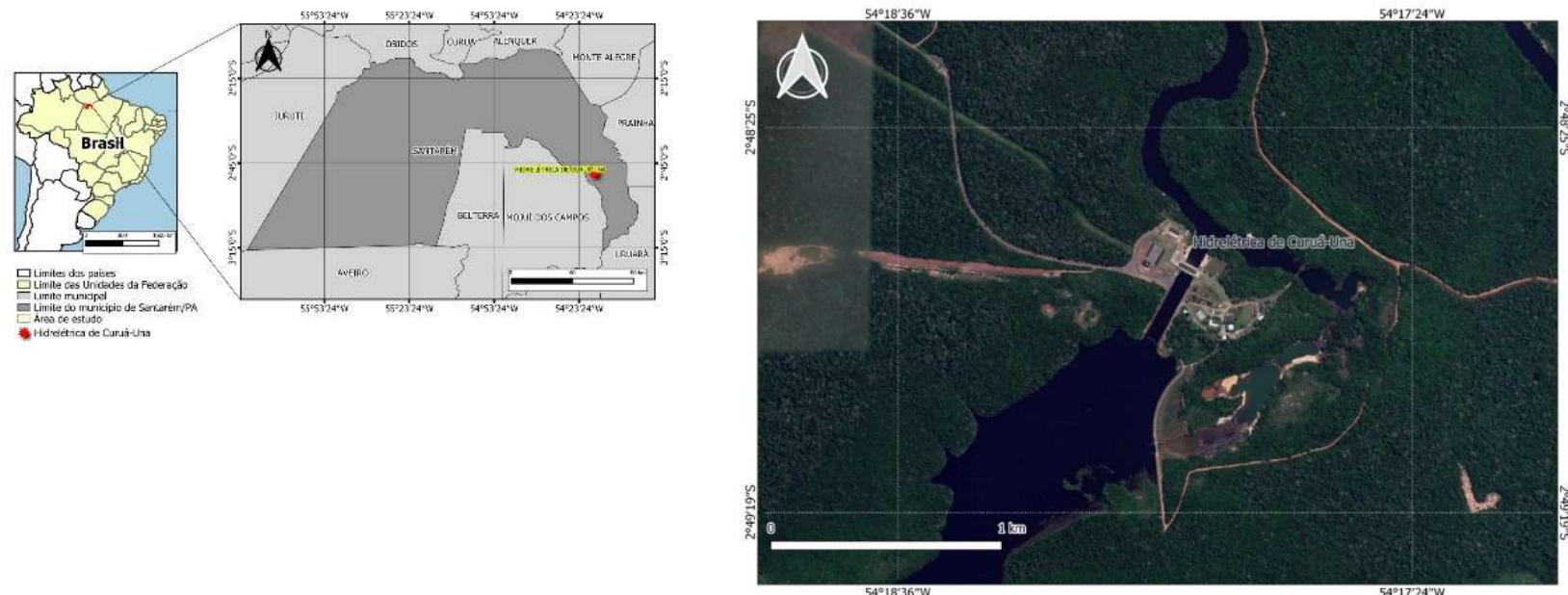

Figura 1: Localização da Usina Hidrelétrica de Curuá-Una em Santarém/PA.

A precipitação média anual em torno de 1820 mm (classe Ami conforme sistema Köppen). Ao contrário da temperatura, o regime de chuvas apresenta grande variação durante o ano, com o maior volume de precipitações ocorrendo nos meses de janeiro a maio. A vegetação de terra firme mais frequente é a Floresta Ombrófila Densa, vegetação dominante no norte do país e que abrange a maior parte dos estados do Pará, Amazonas, Amapá e Roraima.

\section{Análise das Variáveis Hidrométricas}

Os dados pluviométricos foram obtidos através da estação automática de Curuá-Una, localizada a montante da barragem, estes foram obtidos no Sistema Integrado de Dados Ambientais (SINDA), do Instituto 
Influência do El Niño Oscilação Sul - ENOS - (2015/2016) no regime hidrológico e geração de energia na usina hidrelétrica de Curuá-Una,

de Pesquisas Espaciais (INPE), via webํ․ Para as análises fluviométricas foram utilizadas informações do nível do rio, vazão, fluxo de energia e produção de energia através dos dados cedidos pelo Operador Nacional do Sistema (ONS) da Eletrobrás todos os dados foram analisados para o biênio 2015 e 2016.

Foram calculadas as médias mensais para o biênio (2015/2016), os gráficos para análise de variabilidade anual e mensal da precipitação pluviométrica, vazão afluente, turbinada e vertida. Também, foram calculados os totais de precipitação e números de dias com chuva para o período anual e mensal. Para avaliação dos impactos na geração de energia utilizou-se dados e gráficos correlacionados ao fluxo de energia e geração de energia do mesmo período. As respectivas análises estatísticas e saídas gráficas foram realizadas no software $R$ - 3.3.3 (R CORE TEAM, 2014).

\section{RESULTADOS E DISCUSSÃO}

\section{ENOS - El Niño Oscilação Sul (2015-2016)}

Observou-se que de janeiro a junho de 2015 foi o período de maior precipitação pluvial com destaque para o mês de maio que apresentou maior volume de precipitação, aproximadamente $650 \mathrm{~mm}$, com 25 dias de chuva consecutivos para este mês. No entanto, de julho de 2015 a abril de 2016 apresentou o período seco da região, com destaque para os meses de outubro e novembro, onde houve ausência de chuvas, caracterizando um período extremo de seca. De janeiro a abril de 2016 apresentou média de 100 mm, indicando baixo volume pluviométrico. No mês de maio de 2016 houve um aumento na precipitação pluvial (200 mm). Com destaque para agosto de 2016 que foi o mês de menor precipitação abaixo de $50 \mathrm{~mm}$. Verifica-se que dezembro de 2016 foi o mês em que a precipitação teve um aumento, superior a $200 \mathrm{~mm}$ e com chuvas diárias na primeira quinzena e ausência de chuva na segunda quinzena. Os dados evidenciaram que houve uma significativa redução no volume de chuvas a partir de julho de 2015 e continuaram em 2016 com eventos extremos de seca em outubro, novembro e dezembro de 2015 (FIGURA 2).

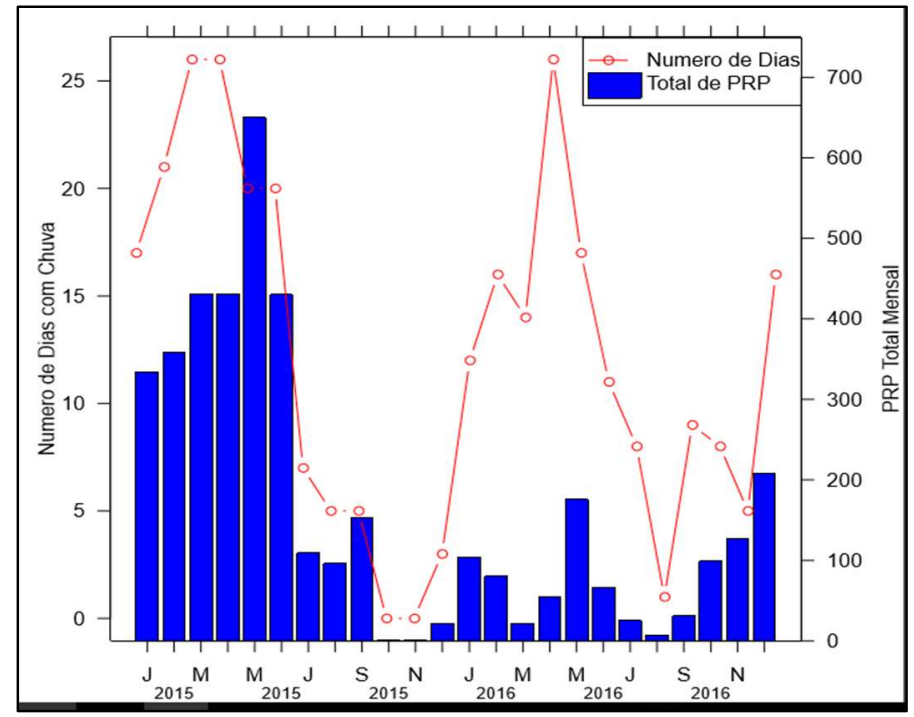

Figura 2: Total mensal de precipitação pluvial (mm) e com números de dias com chuva para período de 2015 a 2016 para a Hidrelétrica de Curuá-Una em Santarém/PA.

${ }^{1}$ http://www.sinda.crn2.inpe.br/PCD/ 
Segundo o Centro de Previsão do tempo e Estudos Climáticos - CPTEC de abril de 2015 a abril de 2016 foi caracterizado pela influência do fenômeno El Niño, classificado pelo CPTEC como um episódio de intensidade muito forte ${ }^{2}$. Sob o ponto de vista hidrológico, as mudanças nas condições atmosféricas produzem impactos significativos na intensidade e distribuição espacial das chuvas, afetando o volume de água dos reservatórios das hidrelétricas (GURJÃO et al., 2012).

Os meses mais secos, são setembro, outubro e novembro, onde, a mediana da PRP ficou em torno de $50 \mathrm{~mm}$ e o número de dias com chuva em torno de 5 dias. Enquanto outubro é o mês que apresenta o menor número de dias com chuva (5 dias). Podemos destacar os meses de setembro, outubro e novembro como sendo os mais secos, com apenas, média de 5 dias com chuva (OLIVEIRA et al., 2018).

Ao analisar o nível do rio a montante e a jusante da usina hidrelétrica de Curuá-Una no biênio 2015/2016 associado aos efeitos do El Niño na região, verificam-se, que as cotas a montante no períoodo de agosto de 2015 a abril de 2016 as médias do reservatório reduziram, com valores abaixo de 65 m, chegando a um limite mínimo de $60 \mathrm{~m}$ em novembro de 2015 (Figura 3a). Enquanto o nível a jusante manteve uma média baixa constante entre 45 a 50 m aproximadamente, com valor mínimo registrado em novembro (44 m) (Figura 3b).

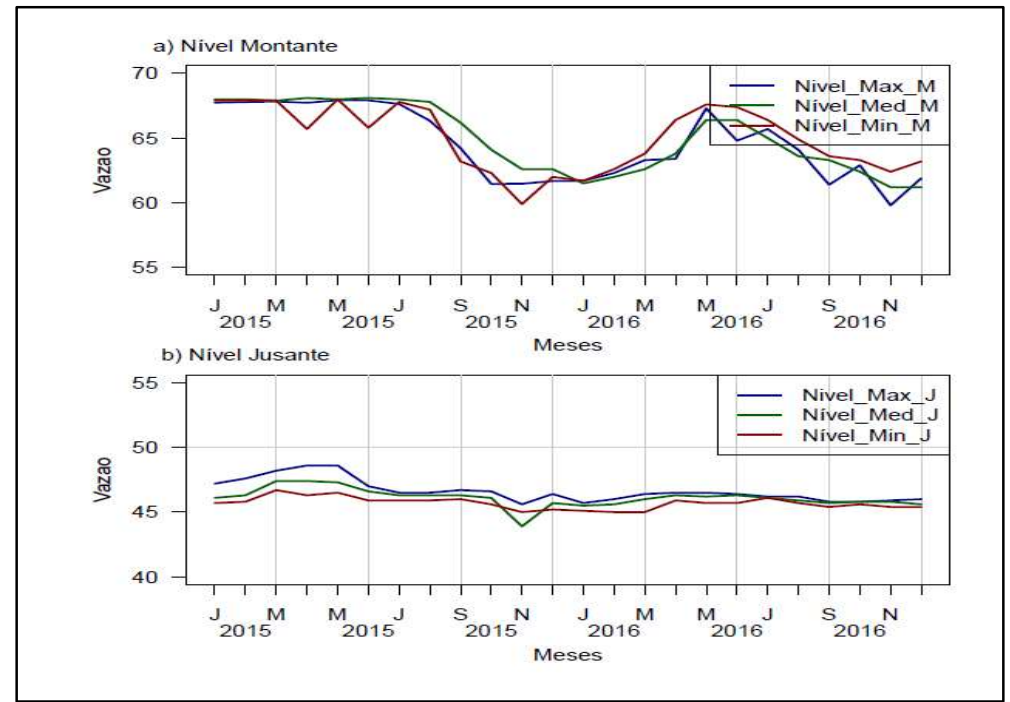

Figura 3: Nível mensal à montante do reservatório de Curuá-Una (a); Nível mensal à jusante do reservatório de CuruáUna (b) em Santarém-PA para o período de 2015 a 2016.

A variação do nível a montante está relaciona ao período em que a anomalia se intensifica (outubro de 2015 a fevereiro de 2016), conforme já foi observado, devido à ausência de chuvas referentes ao mesmo período. O que também justifica o baixo valor a jusante demonstrando a falta de excedente da vazão difluente. Contudo, a redução do nível do rio acarreta impactos negativos na energia gerada pela usina de Curuá-Una, ocasionando uma diminuição na potência gerada. Segundo dados fornecidos pela ELETROBRÁS, nos meses intensos de seca, a U.H.E de Curuá-Una já operou apenas com duas turbinas.

Nesta seção se busca avaliar os impactos do ENOS (2015/2016) sobre recurso hídrico que comporta o funcionamento da barragem, na vazão mensal do reservatório de Curuá-Una. A vazão afluente média foi

\footnotetext{
${ }^{2}$ www.cptec.inpe.br
} 
Influência do El Niño Oscilação Sul - ENOS - (2015/2016) no regime hidrológico e geração de energia na usina hidrelétrica de Curuá-Una,

maior de março a maio de 2015 (300 m³/s). A vazão afluente máxima foi observada em abril de 2015 (400 $\mathrm{m}^{3} / \mathrm{s}$ ), enquanto, que no período de outubro a dezembro de 2015 foram registrados os menores valores. As vazões afluentes mínimas foram registradas de outubro a dezembro de 2015. Foi possível detectar duas grandes cheias extremas nos anos de 2009 e 2014, enquanto, os anos de ocorrência de secas extremas são evidenciados em 2005 e 2010 (Figura 4). Podemos destacar que o recorde da média nível do rio para o ano de 2009 foi de $550 \mathrm{~cm}$ e para o ano de 2014 cerca de $600 \mathrm{~cm}$ (Figura 4).

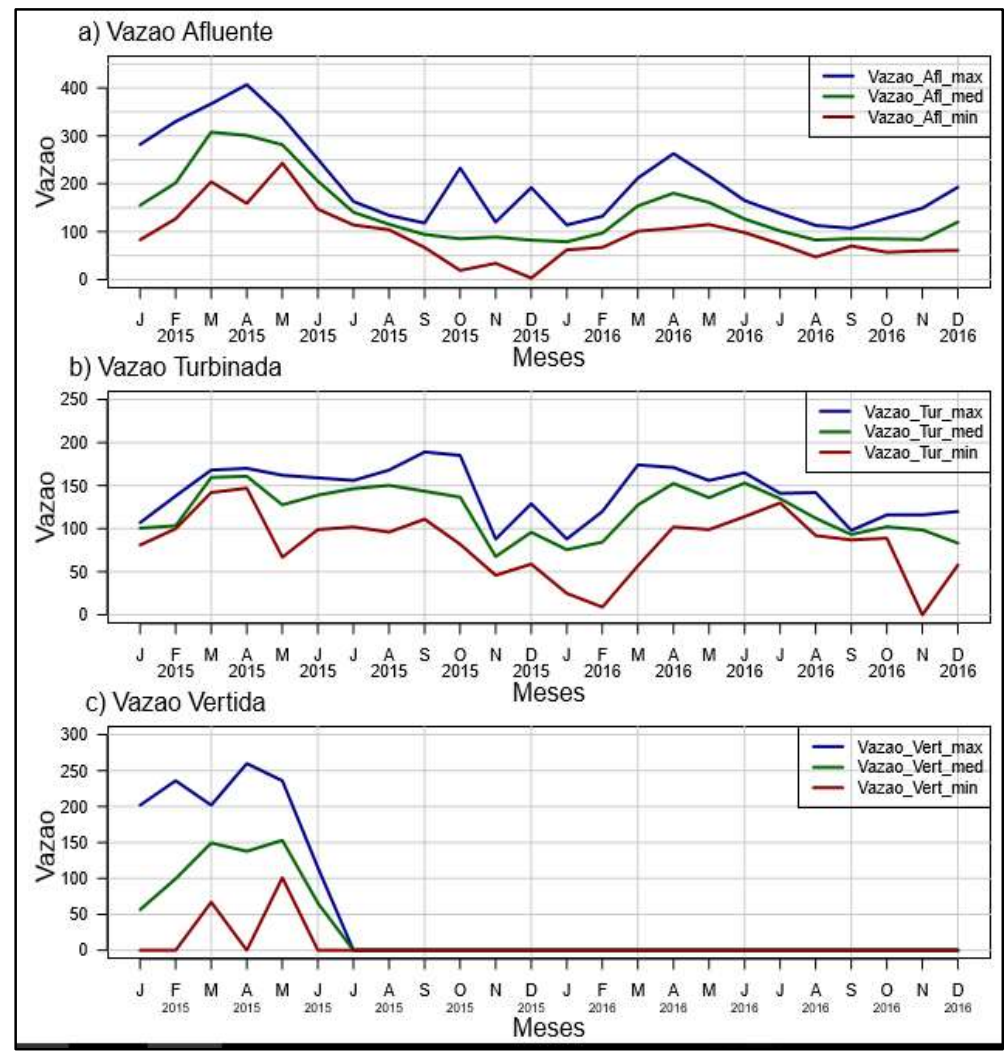

Figura 4: a) Vazão afluente; b) Vazão turbinada; c) Vazão vertida no reservatório de Curuá-Una em Santarém/PA para o período de 2015 a 2116 .

Na figura 4b é analisada a vazão turbinada e suas variações quanto ao valor máximo detêm-se 190 $\mathrm{m}^{3} / \mathrm{s}$ em setembro e outubro de 2015, já em 2016 o limite de $170 \mathrm{~m}^{3} / \mathrm{s}$ em março e abril. Para a vazão turbinada média $152 \mathrm{~m}^{3} / \mathrm{s}$ em março e abril. No ano de 2016 a média turbinada foi de $150 \mathrm{~m} / \mathrm{s}$ nos meses de abril e junho. O limite mínimo da vazão turbinada ocorreu em dezembro 50 m³/s em 2015 e em 2016 ao extremo nos meses de fevereiro e novembro. No resultado de vazão turbinada o pico de menor valor ocorreu nos meses com menor pluviosidade demonstrando que o evento ENOS 2015-2016 modificou o regime hidrológico com fortes impactos no reservatório de Curuá-Una. Na análise da vazão vertida o período de julho de 2015 a dezembro 2016 houve uma constante no vertimento com valores nulos (Figura 4c).

Observa-se que os maiores valores de vazão afluente no biênio 2015/2016 coincidem com o período chuvoso da região, visto que os maiores valores de vazões ocorreram no período de maior precipitação (março a maio), também, evidencia-se que o período chuvoso de 2015, não apresentou influência de El Niño, por isso, teve maior volume de precipitação e vazão comparado com o período chuvoso de 2016 que foi influenciado por El Niño de maior intensidade. Evidenciou-se que a vazão média no período chuvoso decai 
Influência do El Niño Oscilação Sul - ENOS - (2015/2016) no regime hidrológico e geração de energia na usina hidrelétrica de Curuá-Una, Amazônia central

OLIVEIRA, L. L.; SILVA, T. M. R.; BARRETO, N. J. C.; CANANI, L. G. C.; ALMEIDA, R. M.

em torno de $150 \mathrm{~m}^{3} / \mathrm{s}$, quando o período chuvoso for influenciado por El Niño muito forte como evidenciado em 2016. A partir desta análise se pode afirmar que o fenômeno El Niño interfere significativamente no comportamento da vazão afluente.

\section{Relação do El Niño com a Geração de Energia}

A geração de energia no reservatório de Curuá-Una quanto ao fluxo produzido mensal e anual nos anos 2015 e 2016. Observa-se que nos meses de novembro, dezembro de 2015 e janeiro de 2016 foram influenciados significativamente pelo El Niño e constituindo-se menores valores de geração de energia. A capacidade máxima produzida é de $30 \mathrm{MW} / \mathrm{h}$ nos meses de maior vazão. A geração de energia máxima entre os meses com vazão reduzida é de $25 \mathrm{MW} / \mathrm{h}$ em dezembro com média de $15 \mathrm{MW} / \mathrm{h}$ e mínima geração em novembro 2015 e janeiro de 2016 de 10 MW/h. Para produzir energia é necessário o fluxo de água. A redução da vazão diminui a potência gerada (Figura 5).

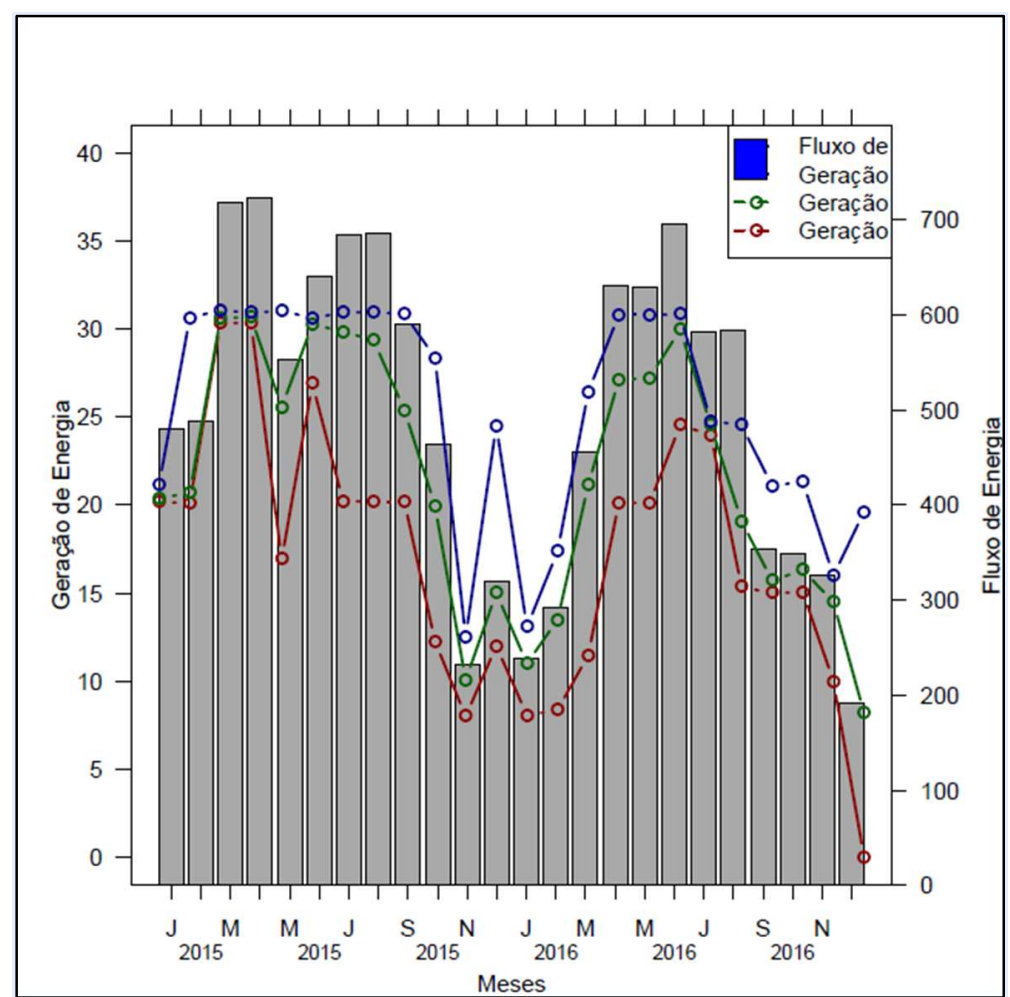

Figura 5: Gráfico representativo da geração de energia quanto ao fluxo de energia no reservatório de Curuá- Una em Santarém-PA para o período de 2015 a 2016.

Tais resultados apontam variabilidades significativas quanto ao regime hidrológico e fluviométricos e na geração de energia do reservatório de Curuá-Una. De acordo com o CLIMATEMPO nos anos de 2015/2016 foi de forte a intensidade da presença de uma anomalia positiva, caracterizada por um aquecimento superior a $0,5{ }^{\circ} \mathrm{C}$ e por três trimestres consecutivos. $\mathrm{O}$ comportamento da vazão turbinada indica que o tempo de resposta do reservatório aos impactos na geração de energia hidráulica surge a partir de novembro de 2015 chegando ao extremo em fevereiro de 2016 com repetição em dezembro do mesmo ano.

Em anos extremos de seca o nível do rio Tapajós em Santarém/PA se afasta $100 \mathrm{~cm}$ da média histórica 
Influência do El Niño Oscilação Sul - ENOS - (2015/2016) no regime hidrológico e geração de energia na usina hidrelétrica de Curuá-Una, Amazônia central

OLIVEIRA, L. L.; SILVA, T. M. R.; BARRETO, N. J. C.; CANANI, L. G. C.; ALMEIDA, R. M.

(OLIVEIRA et al., 2018). Os fenômenos climáticos chamados, dipolo do Atlântico, combinado com uma tendência para o aquecimento regional durante o evento El Niño ou La Niña (VALE et al., 2016) e o posicionamento da Zona de Convergência Inter Tropical - ZCIT podem estar associados aos eventos extremos de seca e cheias do Tapajós e Amazonas (LIMA et al., 2019; VALE et al., 2016).

O rio Amazonas, durante a estação seca de 2016, foi influenciado por uma prolongada tendência climática do El Niño (2014, 2015 e 2016) (LIMA et al., 2019). As vazões amazônicas apresentam altas correlações com os campos de anomalias de temperatura de superfície do mar nos oceanos Pacífico e Atlântico Tropical, o que sugere uma possível associação entre vazões extremas e El Niño, ou um aquecimento no Oceano Atlântico Norte Tropical (MARENGO et al., 2008). Segundo Mori (2016) a deficiência de chuva leva a restrições operativas de usinas hidrelétricas, em razão do baixo volume dos reservatórios. Este fato causa impactos energéticos negativos à operação do Sistema Interligado Nacional (SIN). Contudo, os resultados levam a frequência de eventos extremos durante o ciclo sazonal e sob o efeito do ENOS, influenciando diretamente o potencial energético da Usina de Curuá-Una. O ciclo sazonal nos níveis do rio é de fundamental importância na operação de barragens hidrelétricas e em períodos de baixa água a geração de energia hidrelétrica está sujeita a reduzir (VALE et al., 2016).

\section{CONCLUSÕES}

A atuação do fenômeno climático El Niño (2015/2016) resultou: Na redução em torno de $50 \%$ na precipitação pluvial no período chuvoso e no período menos chuvoso, com ausência de precipitação nos meses de outubro e novembro. No decaimento do nível do reservatório a montante, chegando a $60 \mathrm{~m}$. Na redução (em torno de $150 \mathrm{~m}^{3} / \mathrm{s}$ ) na vazão média no período chuvoso, influenciado por El Niño muito forte como o que ocorreu em 2016 e o decaimento da geração média de energia de $25 \mathrm{MW} / \mathrm{h}$ para $10 \mathrm{MW} / \mathrm{h}$. Os resultados mostram que o regime hidrológico do reservatório de Curuá-Una foi fortemente afetado pela atuação do ENOS com consequente redução da geração de energia elétrica.

\section{REFERÊNCIAS}

AgOSTINHO, A. A.; PELICICE, F. M.; GOMES, L. C.. Dams and the fish fauna of the Neotropical region: impacts and management related to diversity and fisheries. Brasilian Journal of Biology, v.68, n.4, p.1119-1132, 2008.

ARAÚJO, R. C.. Uma comparação entre a bacia do rio CuruáUna e a Bacia do rio Uraim: efeitos do desmatamento sobre o ciclo hidrológico. Tese (Doutorado em Desenvolvimento Sustentável do Trópico Úmido) - Universidade Federal do Pará, Bélem, 2007.

CARVALHO NETO, J. G.; SILVA, R. M.; MONTENEGRO, S. M. G. L.. Análise espaço temporal da precipitação e da vazão na bacia do rio Una, Estado de Pernambuco. In: SIMPÓSIO DE RECURSOS HÍDRICOS DO NORDESTE, 12. Anais. Natal, 2014. p.2-10.
DALLEDONNE, G. L.. Variabilidade e previsibilidade de vazões com o uso da previsão climática de chuva. Curitiba: Universidade Federal do Paraná, 2011.

GURJÃO, C. D. S.; CORREIA, M. F.; CHAVES FILHO, J. B.; ARAGÃO, M. R. S.. Influência do ENOS (El Niño-Oscilação Sul) no Regime Hidrológico do Rio São Francisco: uma Análise em Regiões com Fortes Pressões Antrópicas. Revista Brasileira de Geografia Física, n.4, p.774-790, 2012.

LIMA, N. S.; OLIVEIRA, A. M.; FAÇANHA FILHO, E. B.; BRAGA J. O. N.; FIGUEIREDO, R. S.; CALAZÃES, R. M.; QUISPE, W. D.; VALE, R. S.; FERREIRA, A. S.. Reduction In Water Levels And Regional Warming Of The Amazon River From Peru To The Atlantic Ocean In Brazil Due To The Effects Of The 2016 ENSO. Revista Brasileira de Geofísica, v.37, p.83-94-94, 2019. 
MARENGO, J. A.. Água e mudanças climáticas. Estudos Avançados, v.22, n.63, p.83-93, 2008.

MORI, C. R. R.. Rebaixamento dinâmico em reservatórios de usinas hidrelétricas: estudo de caso aplicado à bacia do rio Iguaçu. Brasília: Universidade de Brasília, 2016.

OLIVEIRA, L. L.; MORTATI, A. F.; BARRETO, N. J. C.. Eventos extremos climáticos e seus efeitos na variabilidade hidrológica do rio Tapajós em Santarém/PA, Amazônia, Brasil. In: CONGRESSO BRASILEIRO DE ÁREAS ÚMIDAS, 4. Anais. Brasília, 2018.
R CORE TEAM. R: A language and environment for statistical computing. Vienna: R foundation for statistical computing, 2014.

REIS, J. F.; SOUZA, W. L. C.; JORGE FILHO, S. L. O.. Medição da vazão da usina hidrelétrica de Rocandor. Curitiba: Universidade Tecnológica Federal do Paraná, 2011.

VALE, R. S.; GOMES, A. C. S.; SANTANA, R. A. S.; TOTA, J.; MILLER, S. D.; SOUSA, R. A. F.. Hydroclimatic variables associated with El Nino and La Nina events at the Curuá-Una hydroelectric reservoir, Central Amazonia. Revista Acta Amazônica, v.46, p.303-308, 2016.

A CBPC - Companhia Brasileira de Produção Científica (CNPJ: 11.221.422/0001-03) detém os direitos materiais desta publicação. Os direitos referem-se à publicação do trabalho em qualquer parte do mundo, incluindo os direitos às renovações, expansões e disseminações da contribuição, bem como outros direitos subsidiários. Todos os trabalhos publicados eletronicamente poderão posteriormente ser publicados em coletâneas impressas sob coordenação da Sustenere Publishing, da Companhia Brasileira de Produção Científica e seus parceiros autorizados. Os (as) autores (as) preservam os direitos autorais, mas não têm permissão para a publicação da contribuição em outro meio, impresso ou digital, em português ou em tradução. 